DOI: $10.33947 / 1980-6469-v 15 n 1-4008$

\title{
TEATRO: A ARTE COMO ATIVIDADE DE RESISTÊNCIA E DE SUPERAÇÃO DE PRECONCEITOS E VIOLÊNCIAS: UMA EXPERIÊNCIA
}

\begin{abstract}
THEATER: THE ART AS ACTIVITY OF RESISTANCE AND OF PREVENTING PRECONCEPTIONS AND VIOLENCES: AN EXPERIENCE

Leslie Evelyn Ruth Marko ${ }^{1}$

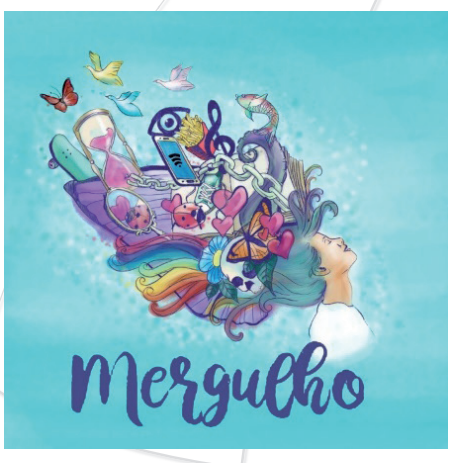

Penso que o Teatro é, durante algumas horas, uma utopia. Pessoas que respiram juntas, que não se matam, que não brigam o tempo todo, que se olham, que se falam.

O teatro é um reflexo do que o mundo poderia ser.

Ariane Mnouchkine, Diretora do Théâtre du Soleil

\section{RESUMO}

Este artigo se propõe a relatar e a analisar aspectos de uma experiência pedagógico-teatral dirigida a jovens de escolas municipais vinculadas aos Centros Educacionais Unificados (CEU) de São Paulo entre 2016 e 2017. O espetáculo MERGULHO, apresentado pela Companhia Gesto de Teatro busca, por meio da linguagem cênica, fomentar a tolerância e coexistência de identidades culturais, religiosas e étnicas diferentes. Este artigo busca responder a seguinte questão: Quais são os significados que esta experiência teatral traz aos jovens e Professores? Percorrendo as diferentes fases do projeto MERGULHO, que consiste na realização de ação dirigidas para o exerício de reflexões sobre os preconceitos e discrimições sociais, o texto analisa as diferentes atividades de interação com o público, oficinas, debate coletivo e a redação de cartas sobre como a peça os mobilizou e quais caminhos eles sugeriam para as questões que esta levanta. Compartilharei também fragmentos das cartas mencionadas. Parte importante das conclusões refere-se à importância da prática pedagógica e teatral como um processo de exercício individual e coletivo de conscientização contra situações de preconceito, intolerância e discriminação, presentes na sociedade que habitamos.
\end{abstract}

PALAVRAS-CHAVE: Teatro-Educação. Discriminação. Preconceitos. Jovens. Professores

\section{ABSTRACT}

This article proposes to report and analyze aspects of a theatrical pedagogical experience directed at young students of municipal schools linked to Unified Educational Centers (CEUs) of São Paulo between 2016 and 2017. The play MERGULHO presented by the Companhia Gesto de Teatro seeks, through scenic language, to foster the tolerance and coexistence of different cultural, religious and ethnic identities. This article seeks to answer the following question: What are the meanings that this theatrical experience brings to young people and teachers? Through the phases of the MERGULHO project, which consists in the accomplishment of actions directed to the exercise of reflections on social prejudices and discriminations, the text analyzes the different activities of interaction with the

1 Doutora e Mestre em Direção e Teatro-Educação pela Escola de Comunicações e Artes (ECA) e Faculdade de Filosofia, Letras e Ciências Humanas (FFLCH) da Universidade de São Paulo (USP). Docente da Escola Superior de Propaganda e Marketing (ESPM). Desenvolve programas de Mentoria Pedagógica no Brasil e no exterior. Pesquisadora do Laboratório de Etnografia, Discriminação e Racismo (LEER)/ USP. Diretora do espetáculo MERGULHO para jovens e adultos sobre diversidade e coexistência. Docente da Escola Superior de Propaganda e Marketing (ESPM) no Curso de Ciências Sociais e de Consumo (CISO). 
public, workshops, collective debate and the writing of letters about how the play mobilized them and what paths they suggested for the issues raised by the play. I will also share fragments of the mentioned letters. An important part of the conclusions refers to the importance of pedagogical and theatrical practice as a process of individual and collective exercise of awareness against situations of prejudice, intolerance and discrimination present in the society we inhabit.

KEYWORDS: Theater Education. Discrimination. Prejudices. Young people. Educators

\section{Primeiro Sinal...}

Este artigo faz parte do meu histórico como diretora de espetáculos dirigidos a jovens nos últimos 35 anos e teatro-educadora ${ }^{2}$.

Através da prática do Teatro Educação podemos favorecer a formação de grupos teatrais juvenis em comunidades com pouco ou nenhum acesso à cultura. Está iniciativa permite tanto para atores como para espectadores, representantes de uma sociedade que queremos melhorar, utilizar o teatro como valioso recurso educacional a serviço de questionamentos e transformações possíveis em busca de uma sociedade melhor.

A partir do meu percurso na PUC do Peru e na USP em épocas em que o a formação teatral era baseada em autores engajados como Bertolt Brecht (Alemanha), Enrique Buenaventura (Colômbia) e Augusto Boal (Brasil), pude construir um olhar para um Teatro social e pedagógico com a preocupação em realizar encenações dirigidas a públicos de segmentos da população, como produtores ou como espectadores, com pouco acesso à arte e à cultura.

Os trabalhos realizados tiveram sempre por característica realizar encenações a partir do jogo teatral, como expressão estética de tradução da realidade. Assim, as montagens trazem à tona o conceito do brincar como necessário no fazer humano. Criei, encenei e apresentei, junto com colegas, estudantes da USP (década de 70), o espetáculo SIMULADO, apresentado em escolas, cursinhos e faculdades, sobre os conflitos dos jovens diante do Vestibular (pressão, indecisão, mercado de trabalho no futuro, etc.) e agora abriria o leque sobre aspectos em torno da juventude em geral. Este espetáculo foi essencial para

2 Uso o termo teatro-educador, de acordo com a teatróloga Joana Lopes (1981), relacionado ao especialista que usa o teatro para promover o desenvolvimento pessoal e grupal inserido em um contexto social e político. consolidar uma forma de linguagem e estética assim como no aprofundamento da temática sobre o Jovem. Apresentações forneceram repertório para continuar pesquisando a respeito.

\section{Segundo Sinal...}

Após o projeto SIMULADO, sentimos a necessidade de dar continuidade ao pensar do fazer pedagógico teatral que mobilize e sensibilize como uma experiência e não apenas como uma informação a mais no painel contemporâneo de estímulos acelerados onde não podemos perder nenhuma faísca no caminho abrupto das informações ${ }^{3}$. Neste sentido, é essencial, por meio do teatro, tocarmos reflexivamente jovens e adultos, Professores e estudantes.

Dentre os objetivos que tínhamos, um novo grupo de Professores e teatro-Professores nos anos 80, estavam: promover a reflexão do público acerca do papel do jovem na sociedade contemporânea; a intolerância e preconceito na nossa sociedade; resgatar e valorizar a identidade cultural de grupos pouco considerados na cultura; estimular a presença das artes cênicas na cultura brasileira; incentivar a formação de público teatral e fomentar a prática de espetáculos teatrais.

Foi realizada uma pesquisa para melhor entender o olhar do jovem: seus sonhos, anseios, angústias e esperanças. Também nos perguntamos sobre as intersecções com as instituições onde ele/ ela se insere no cotidiano como a família, escola, lazer, drogas, sexualidade, amor, amizade, violência, etc. Estes aspectos precisariam se entrecruzar com questões relacionadas à diversidade. Lemos livros e artigos, assistimos filmes, conversamos com psicanalistas, entrevistamos profissionais que trabalham com jovens nas áreas de entretenimento, propaganda $e$

3 Sugiro ler o artigo de Larrosa-Bondia (2002). 
literatura, visitamos e conversamos com integrantes da Pastoral da Juventude, revisitamos aspectos da nossa própria juventude e, finalmente, organizamos uma Oficina teatral com jovens.

Construímos um texto dramatúrgico de forma coletiva retratando, analisando e representando o universo pesquisado, posteriormente traduzido cenicamente. O texto e a encenação nos representavam um olhar crítico em relação aos jovens e os espaços de inclusão e exclusão vividos por estes. Criamos então três personagens com diferenças socioeconômicas, emocionais e com posicionamentos diversos diante da sociedade.

Assim foi elaborado o espetáculo teatral MerguIho, uma criação coletiva com 75 minutos de duração dirigido a adolescentes, professores e funcionários de instituições escolares; pais, familiares e público em geral.

No palco, a dinâmica dos atores se desenvolveu de forma lúdica. A cenografia, os figurinos e os acessórios respondem a uma composição que acompanha cada identidade diferente e singular do jovem, seus universos reais e imaginários. Assim, o uso prático de cada objeto em cena e a sua transformação em novos objetos, permitiu que a concepção imaginativa da estética da peça transformasse um cubo em mesa de bar ou em mesa de uma casa onde se celebram as festividades, conflitos e diálogos possíveis no decorrer da peça.

Apresentado em escolas, associações e clubes, durante duas décadas, a peça teatral Mergulho passou por diversas transformações até chegar na versão atual.

\section{Terceiro Sinal...}

Uma nova versão...

Depois de apresentar durante alguns anos diversas versões de MERGULHO, sempre com debates no final com o público, com repercussão significativa, fomos convidados pela Bnai Brith, instituição judaica ligada a Direitos Humanos em parceria com a Secretaria Municipal de Educação para apresentar o espetáculo em Centros Educacionais Unificados (CEU) ${ }^{4}$ dos polos norte, sul, leste e oeste de São Paulo, com

4 Centros Educacionais Unificados criados como equipamentos públicos voltados à Educação de São Paulo e situados na periferia da Grande São Paulo. a finalidade de promover a discussão vinculada também a Direitos Humanos. Para tal, realizamos alguns ajustes. Adaptamos nossos três personagens para que representassem claramente grupos étnicos/culturais, tornando-se metáforas de minorias que convivem numa cidade como São Paulo contribuindo com aportes sociais e culturais, de preservação, continuidade e celebração. Símbolos pesquisados das culturas retratadas no espetáculo surgiram, em diversos momentos, como elementos constitutivos das diferentes identidades. Realizamos novas pesquisas com antropólogos, psicanalistas e sociólogos. Novos objetos foram incorporados ao cenário e aos figurinos.

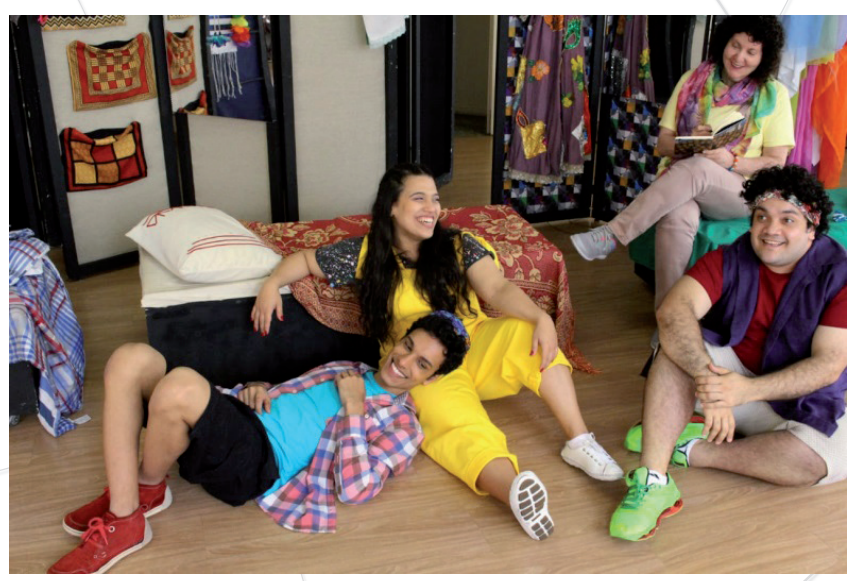

Ensaio de MERGULHO

Na versão apresentada, por meio dos três personagens, são expostas formas de discriminação na História Social, na identidade familiar e no mosaico cultural da nossa civilização mais recente e seus reflexos no cotidiano: antissemitismo em relação aos judeus no Holocausto, escravidão dos negros e discriminação dos indígenas no Brasil e o preconceito contra migrantes nordestinos ou imigrantes orientais/ coreanos, venezuelanos ou haitianos. A encenação reforça a importância de sensibilizarmos e fomentarmos a tolerância e coexistência de identidades culturais, religiosas e étnicas diferentes. O projeto sublinha a importância da alteridade, respeito e diversidade na construção permanente do Humanismo.

Esta temporada se estendeu durante dois anos (2016-17). Criou-se um modelo pedagógico orientado a professores e alunos do Ensino Fundamental II nas Escolas Municipais organizadas pelas Diretorias Re- 
gionais de Educação (DREs) vinculadas a cada CEU, sendo um total de 24 apresentações (6000 jovens espectadores) e 16 Oficinas com professores (200) em 4 CEUs diferentes ${ }^{5}$.

Neste modelo estavam presentes princípios e conceitos veiculados por meio da arte teatral. Partimos da premissa que o teatro, como arte coletiva e lúdica, contribui com o convívio entre as pessoas, a superação de pré-conceitos, reforça o valor da alteridade e o respeito pela diversidade, assim como estimula o trabalho de equipe, a construção do conhecimento em grupo e a articulação estética da expressão e do pensamento, entre outros aspectos da vida do ser humano. Nesse sentido a contribuição de Herbert Read (1986) relaciona-se, como dito anteriormente, com o resgate da dimensão da imaginação na era tecnológica e a importância do ensino da arte para adultos fusionando trabalho e entretenimento.

O Teatro-Educação faz uso de recursos da linguagem teatral que ao longo da história da civilização vem mostrando aportes ao desenvolvimento da abstração, imaginação, criatividade e crítica, diante de como pensamos e sentimos o mundo. $E$ ainda mais: de como podemos contribuir na reflexão e possíveis transformações.

\section{Oficina de Professores 1}

As Oficinas realizadas na Sede da Bnai Brith de São Paulo coordenadas por mim e dirigidas a 25 professores dos adolescentes que assistiriam semanas depois a peça MERGULHO, com duração de 4 horas buscaram:

- Oferecer um espaço de encontro e troca entre Professores de DREs diferentes;

- Oferecer um espaço de teatralidade (utilizando o corpo, a gestualidade, a palavra, o silêncio, a emoção e o intelecto) para trabalhar a expressão individual e grupal em relação a aspectos da discriminação e intolerância nas escolas e na sociedade contemporânea em geral;

5 Apresentamos em 4 CEUs ligados a Direitos Humanos: Casa Blanca, Jardim Paulistano, Pêra Marmelo e São Rafael.
- Identificar e discutir situações de discriminação e preconceito no cotidiano escolar;

- Sensibilizar os Professores para a introdução do tema e o contexto histórico do Holocausto, antissemitismo e racismo em geral nas salas de aula enquanto genocídio singular na História da Humanidade que atentou também contra negros, ciganos, homossexuais, opositores políticos e pessoas com necessidade especiais;

- Estabelecer pontes com situações de discriminação contemporâneas e presentes no cotidiano escolar;

- Sugerir temas e material didático com o objetivo de promover em sala de aula, atividades que fomentem o respeito à diversidade e aos direitos humanos;

- Exemplificar, por meio de obras artísticas produzidas durante o Holocausto e na sociedade contemporânea, formas de expressão diante da barbárie. Alguns exemplos: pinturas de vítimas do extermínio aos judeus (Felix Nussman, 1904-1944), diários de crianças de diversas guerras do século $\mathrm{XX}$ (Vozes Roubadas: diários de Guerra escritos por crianças), desenhos de crianças do Campo de concentração de Terezin 6 , pintura de Tarsila do Tarsila do Amaral (Operários - 1933), imagens do mímico francês Marcel Marceau ${ }^{7}$, para ele, que trabalhou com crianças durante a guerra: "O Homem moderno rodeia-se de possibilidades infinitas de comunicação e, paradoxalmente, é o que sempre Ihe falta", etc.

6 Exposição itinerante que veio ao Brasil em 2017 exposto no MuBE: "As meninas do Quarto 28: desenhos de meninas sobre o dia a dia no campo de concentração de Therezin, na República Tcheca".

7 Mímico francês (1923-2007), de origem judaica, perdeu seu pai em Auschwitz e participou nas Forças Francesas Livres durante a guerra. Reconhecido mundialmente pela sua "arte do silêncio". O gênio da mímica, que gostava muito de conversar, afirmava que, apesar de tudo, "a palavra não é necessária para expressar o que se tem no coração". 


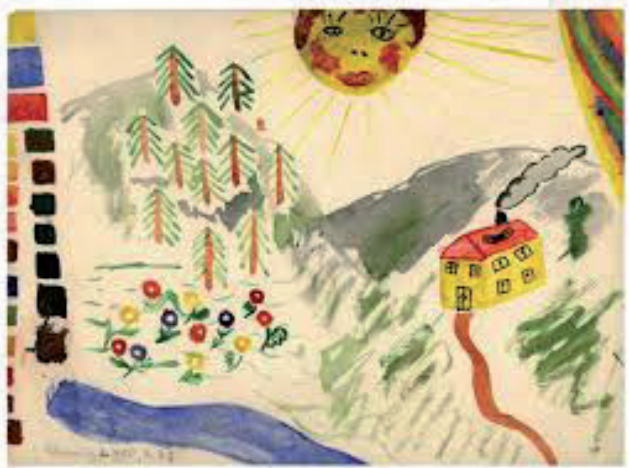

Desenhos de criança de Terezin

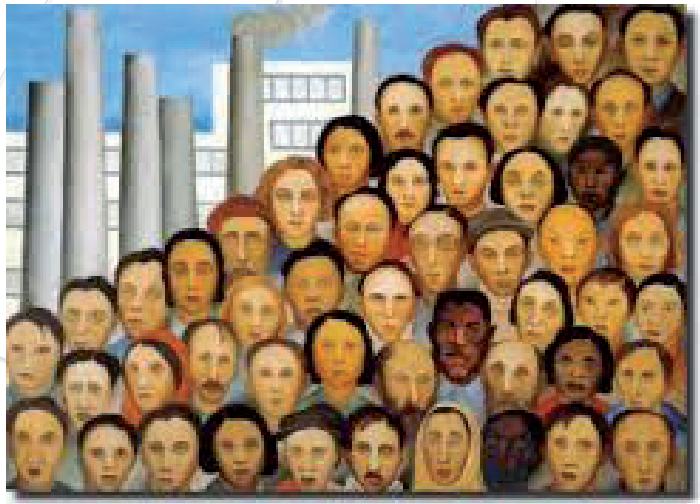

Operários - Tarsila do Amaral (1933)

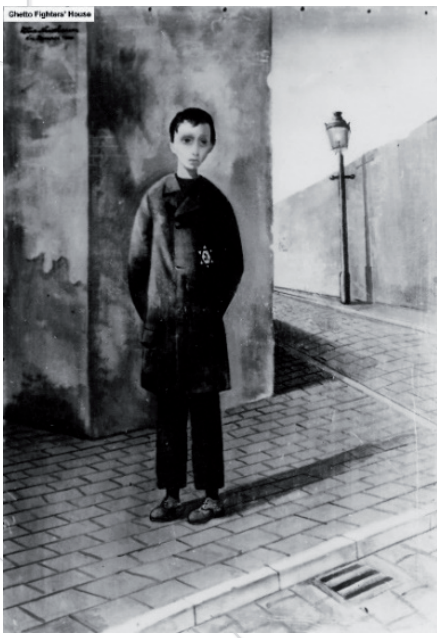

Pintura de Felix Nussman

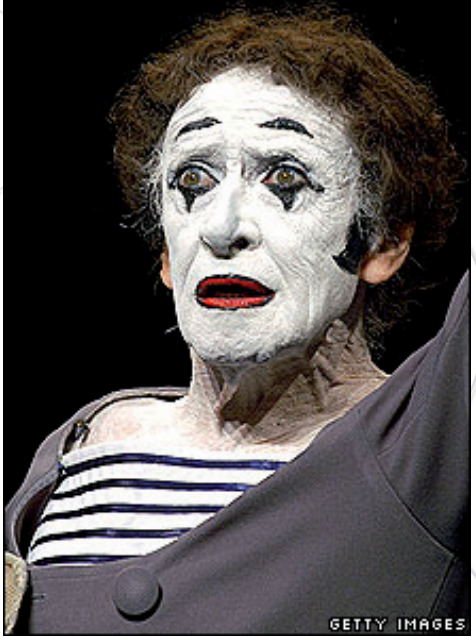

Marcel Marceau

- Favorecer a criação de projetos pedagógicos para que os professores pudessem preparar os alunos para assistirem a peça teatral, em equipes disciplinares e interdisciplinares. Estes projetos sensibilizariam os jovens com a temática dos pré-conceitos e intolerância para melhor mergulharem no espetáculo e na relação com os atores;

- Supervisão destes projetos sobre os quais os professores poderiam dialogar comigo durante a semana prévia à apresentação.

Por meio de dinâmicas, os professores, que não se conheciam, se socializaram através do jogo, do afeto e do humor e estabeleceram, em primeiro lugar, vínculos de confiança entre eles e comigo. A partir da confiança, foram desenvolvidos exercícios para que encontrassem formas diferentes e alternativas de se expressar, associados ao uso da imaginação e da criatividade.

Estas oficinas buscaram, sensibilizar os participantes em relação à compreensão sobre o significado histórico do Holocausto: deixar de situá-lo como produto da loucura de um indivíduo, mas contextualizá-lo num processo histórico onde a concepção e prática do nazi-fascismo por meio do domínio de uma suposta raça superior repetia a necessidade do extermínio generalizado sem tocar a "pureza" germânica. E também promover a consciência, como afirma Sigmund Bauman, de que aspectos do Holocausto revelam carac- 
terísticas cruciais da sociedade da qual somos membros: "O Holocausto nasceu e foi executado na nossa sociedade moderna e racional, em nosso alto estágio de civilização e no auge do desenvolvimento cultural humano". (BAUMAN, 1996, p. 12).

Propomos que os participantes compartilhassem e expressassem aspectos de seus repertórios pessoais e coletivos em relação ao Holocausto: foram construídas imagens a partir de concepções próprias e desenvolvemos imagens com movimento experimentando transformações desejadas e possíveis. Este trabalho foi realizado por meio do Teatro-Imagem, metodologia proposta por Augusto $\mathrm{Boal}^{8}$ que favorece a síntese das ideias por meio de gestos. Trata-se de uma dinâmica fácil e rápida que possibilita que emerjam conteúdos profundos ao mesmo tempo. Evitando a combinação ou qualquer tipo de liderança, os participantes constroem imagens diversas que expressam de forma potente pensamentos e sentimentos diferentes e ao mesmo tempo que se complementam.

Através do contato com a poética teatral e o resgate de textos que expõem as dores de vítimas, fragmentos de diários de jovens e crianças entorpecidos pelo horror e obras artísticas que herdamos dos escombros da catástrofe, os professores, através da vivência na oficina, têm acesso à informação, o alerta, a crítica e principalmente ao exercício da interação provocadora, esteticamente falando... E assim, por meio de dinâmicas e exercícios teatrais espontâneos e elaborados.

No trabalho que os professores realizariam nas escolas, foi importante promover o caráter de protagonismo do próprio jovem na sociedade. Nos espaços de ensino e aprendizagem, podemos promover um exercício de reflexão e atuação sobre o papel do cidadão jovem na sociedade, especificamente a brasileira, no nosso caso, que venha fortalecer a sua própria identidade e seu lugar no mundo.

O acompanhamento da realização dos projetos em cada escola entre o final da Oficina e o dia da apresentação se manteve por meio de e-mails, quando necessário. De forma geral, cada professor teve autonomia para desenvolver seu planejamento, registrar e documentar os resultados.

8 Criador do Teatro do Oprimido resultando em experiências teatrais no Brasil. Argentina, Peru e França, hoje difundido no mundo todo.

\section{Espetáculo MERGULHO e seus ECOS}

Descrevo em tempo presente esta etapa dando o tom de permanência e de repetição, mesmo de forma singular, em cada CEU. Vou narrar uma experiência de uma das apresentações do espetáculo considerando que estas experiências são semelhantes no formato, nos sentidos, nos sentimentos e nas interações, mesmo que com as suas singularidades.

\section{Parte 1: Apresentação}

No dia combinado 250 alunos de duas ou três escolas encontram-se em um dos CEUs ${ }^{9}$.

Todos entram no Teatro, espaço pouco frequentado por este público, ao qual damos as boas-vindas. Uma breve apresentação é realizada pela coordenação do CEU e explicamos para os alunos a proposta do projeto.

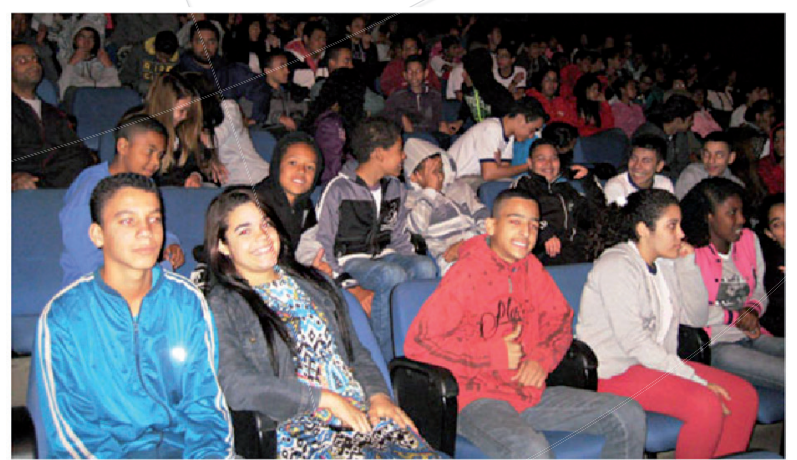

Alunos da EMEF Alceu Amoroso Lima antes do início do espetáculo no CEU São Rafae

Após segundos de silêncio e a luz se apagando em clima de expectativa, a peça se inicia.

A trilha sonora e a iluminação entram com intensidade no palco e assim os 3 personagens pulam dentro numa dança forte e contagiante.

Os professores que participaram da Oficina desenvolvida há duas semanas e que, em seguida, desenvolveram projetos de sensibilização com os alunos no decorrer da semana sentam-se entre os jovens.

Uma hora e quinze minutos de espetáculo são regados a risadas, silêncios, reações e comentários...a maior parte do tempo olhares perplexos e curiosos acompanham as ações e os diálogos da peça teatral. 
Nossos três personagens, Lila, Daniel e Jeremias vão se compondo diante dos espectadores. Cada um com uma identidade étnica, um espaço interno psíquico, um espaço físico (seu quarto), uma família, uma história pessoal singular, horizontes de vida, conflitos, frustrações, anseios, amores. Eles percorrem situações reais e ficcionais como numa montanha russa passando por discórdias e acordos, por momentos de raiva e de solidariedade entre eles e na sua relação com a sociedade, o que lhes permite construir, ao longo da peça, processos de desenvolvimento e de tomada de consciência do que eles são individualmente e como um coletivo.

A seguir exemplifico, neste artigo, por meio de alguns diálogos, de que forma a peça vai se construindo diante dos olhares e pulsações dos jovens e adultos em cima de ações e diálogos que deflagram situações de discriminação e intolerância e como os personagens vão se descobrindo para no final se posicionar com maior clareza sobre a importância do respeito e compromisso com a própria identidade.

A peça se inicia com diálogos que denotam sentimentos de discriminação que os personagens sentem: enquanto dançam diante de espelhos imaginários, que são a própria plateia:

DANIEL: Meus braços estão ficando longos, meu corpo está esquisito...

LILA: Meu rosto está feio, cheio de espinhas...

JEREMIAS: Vão ter que gostar de você como você é!

DANIEL: Não me reconheço, esse corpo não é meu, essa cara, esse cara não sou eu!

JEREMIAS: Qual é o problema de eu ser nordestino? Será que é o meu sotaque?

LILA: $\quad$ A minha cor negra não combina com as minhas roupas...

DANIEL: Às vezes eu não queria que percebessem que eu sou judeu...

JEREMIAS: Não me suporto com tão pouco pelo no corpo...

LILA: $\quad$ Parem de dizer que meu cabelo é bombril!
Logo em seguida, fogem para dentro de seus espelhos montados em dragões mágicos imaginários ingressando na terra da utopia. Após compartilharem uma viagem fantasiosa, ao voltar, reaparecem os conflitos... desta vez Jeremias, nordestino, julga Daniel e sem medir as palavras envereda por um discurso antissemita, que impacta seu amigo:

DANIEL: Vai Jeremias, eu tô numa crise existencial, tô precisando muito de vocês. Para de ser egoísta.

JEREMIAS: Egoísta? E você, seu menininho de prédio criado pela vovó? Para de me encher o saco. Tem que ser tudo do seu jeito. Vai explodir algum prédio, seu homem-bomba ou melhor, dá uma ligadinha pro seu amigo.... Hitler. Já disse que se der eu vou, tchau.

(Entra música e um vídeo com fotos do massacre e da destruição do período do Holocausto enquanto Daniel fala. Jeremias e Lila observam e escutam a fala de Daniel, entristecendo-se junto com ele)

DANIEL: Jeremias não tem ideia do que ele ta falando. Adolf Hitler foi um louco que criou o partido nazista e que por causa da intolerância invadiu países da Europa e queria conquistar o mundo todo. Provocou a morte de milhões de judeus. Inclusive até hoje existe o antissemitismo no mundo. Matou também ciganos, homossexuais, deficientes físicos e mentais e também negros (olha para a Lila). Definitivamente, o JEREMIAS não sabe do que ele tá falando. Hitler despedaçou a Humanidade (slide final de crianças judias).

(Jeremias que ao longo do vídeo, chocado, percebe o que fez e entristece arrependido. Vai ao encontro de Daniel.)

JEREMIAS: Desculpa, Dani. Eu não sabia do que eu tava falando. 
DANIEL: Tudo bem, Jê, quando a gente não sabe do que tá falando, sempre acaba dizendo besteira. Fica experto da próxima vez, ok?

("Tocam" com as mãos voltam para os quartos.)

Desta forma a peça vai tocando em situações agudas de preconceito e intolerância entre os próprios personagens. Estes também criam outros personagens dentro da peça, assumindo outros papéis (metateatro) para melhor identificar outras posições e opiniões.

Cenas de guerra onde jovens são levados injustamente ao front em nome de princípios que não são deles ou conflitos familiares não compreendidos pelos personagens e a própria pesquisa que os personagens realizam na escola para pesquisar sobre suas origens e raízes é que vão trazendo um colorido e composição de suas identidades. É assim que os espectadores percebem que as diferenças identitárias somam, ou seja, trazem valor para a relação dos três amigos.
DANIEL: Ah, filho, unzinho ou dois

LILA: $\quad$ Três ou quatro.....

JEREMIAS: É nada.. Vocês não vem que isso faz mal. Que péssimo exemplo, vocês não acham?

LILA (como marreco) Não entendo porquê há violência nas escolas se aqui, no nosso país não tem nenhum problema de educação, saúde, drogas, trabalho, estupro, saneamento básico...

DANIEL (como marreco) Aqui no nosso país, não tem preconceito e nem discriminação. Somos todos iguais.

JEREMIAS: (como marreco, tentando falar, gaguejando com dificuldade...)

DANIEL Fala direito, seu gago! Assim não dá pra entender nada, meu.

LILA: (Como marreco, dirigindo) Só podia ser mulher! Ô dona Maria, Vai pro tanque lavar roupa!

DANIEL (Como marreco) Filho, por que você come tanto? Desse jeito você vai explodir!

JEREMIAS: (Como marreco) Precisamos respeitar os idosos. Eu amo a terceira idade. Eles são sensacionais. Mas...tá entrando um velhinho no ônibus, finge que tá dormindo! Só para não dar o lugar!

LILA: (Como marreco) Oxente, você tá vestido igualzinho um baiano. Que cafona!

Cena da peça, questionando as guerras onde "meu maior inimigo sou eu mesmo"

Assim é a cena dos "marrecos" quando dezenas de personagens desfilam como pássaros de quermesse enquanto vociferam frases negadoras de sobre preconceitos e intolerantes em relação a drogas, violência nas escolas, gordofobia, gagueira, mulher, nordestino, idosos, homofobia, refugiados, etc. como:

JEREMIAS: Pai, mãe, maconha de novo? (como marreco)
(Daniel e Jeremias como pais conservadores)

JEREMIAS: Eu ando desconfiado ...do meu filho

DANIEL: O que tem seu filho?

JEREMIAS: Eu acho que ele....

DANIEL: Ele?

JEREMIAS: Ele....

DANIEL: Ele é gay...!!?

JEREMIAS: Deus que me livre dessa doença!

LILA: $\quad$ Pera ai gente (todos param) E 
desde quando homossexualidade

é doença?

(Daniel e Jeremias olham-se perplexos)

JEREMIAS: Campainha às $7 \mathrm{~h}$ da manhã, só

pode ser refugiado, boliviano, peruano, sírio, haitiano, angolano...

(Daniel faz som de campainha.)

JEREMIAS: Quem é?

DANIEL: Somos nós....

LILA: $\quad$ Somos nosotros....

DANIEL: Vocês sabiam que tem milhares de refugiados no Brasil sendo bem recebidos por grupos e pessoas que entendem a situação deles e acolhem de verdade?

(Os três se olham curiosos e fazem uma pantomima de abraços e cumprimentos um com outro e todos com todos falando diversas línguas ao mesmo tempo. Não há disparos)

DANIEL:

(Como marreco) Como eu disse antes, aqui no nosso país não temos discriminação nenhuma, todos somos iguais. Votem em mim, vote em mim.

\section{Apresentação/Reações}

A possibilidade dos estudantes e docentes viverem a experiência teatral de forma a que os mobilize e não apenas Ihe traga uma nova informação torna-se significativo da aprendizagem vivida torna-se significativa. Segundo o pedagogo espanhol Larrosa-Bondia,

[...] A experiência é o que nos passa, o que nos acontece, o que nos toca. Não o que se passa, não o que acontece, ou o que toca. A cada dia se passam muitas coisas, porém, ao mesmo tempo, quase nada nos acontece. Dir-se-ia que tudo o que se passa está organizado para que nada nos aconteça (LARROSA-BONDIA, 2002).

Pudemos constatar que o teatro é uma arte que trabalha no aqui e agora com o corpo, o intelecto, a emoção a intuição uma arte que integra as facetas do seu humano para quem atua e quem está participando através de sua recepção como espectador. Se cria um círculo...A gente fala no palco sentimentos e pensamentos que os jovens gostariam de estar expressando. Isso explica por que poucas vezes os jovens usaram seus celulares durante a apresentação. Ficaram a maior parte do tempo vinculados, emocionados, junto!

É importante lembrar que os jovens tinham participado, na escola, de atividades (produto das nossas Oficinas) como forma de sensibilização e exercício de uma cultura de paz e de não violência. Assim a experiência se completaria com a de mergulhar no espetáculo. Tanto nas Oficinas, como nas atividades e no espetáculo valorizou-se enquanto prática, seja no plano do real como no poético-teatral, a inclusão e a coexistência assim como o compromisso com os Direitos Humanos enquanto marco regulador da convivência (JARES, 2008). Na parte final da peça, os personagens confirmam e compartilham entre eles e com os espectadores percepções do desenvolvimento percorrido e inclusive a possibilidade de engajamento em movimentos coletivos:

LILA: $\quad$ Agora eu entendo a importância de entrar para o Movimento Negro. Porque, estando lá dentro, vou poder me preocupar não só com os negros, mas também com outras raças, culturas e etnias que são discriminadas.

JÊREMIAS: Eu nunca imaginei que vocês tivessem passado por tudo isso, e a família de vocês. Vocês são iguais a mim.

DANIEL: Nós todos somos iguais, porque somos diferentes.

LILA: $\quad$ Nossa, que louco, né? Mas é o lance da diversidade! Isso que enriquece o ser humano.

(Os personagens trocam entre si os objetos/ acessórios que os caracterizava - símbolos de identidade: Jeremias entrega a touca para Daniel. Lila entrega o colar para o Jeremias e, Daniel, a quipá pra Lila.)

\section{Parte 2: Debate}

No final da peça propomos um debate com o 
público. Perguntamos à plateia se gostaram, com que momentos da narrativa se identificaram e de que forma a peça os mobilizou. No início muitas vezes instala-se um silêncio que consideramos natural por não ser habitual nem a apresentação teatral desta forma (lúdica e com esta temática) e menos ainda o convite para uma conversa que os inclua sentimentos e vivências pessoais e coletivas). Em um segundo momento, são muitos que querem falar ao mesmo tempo. Surgem questões diretamente ligadas à discriminação vividas por eles: racismo, deficiência física, situação envolvendo refugiados, homofobia, entre outras. A mediação é feita para que as participações sejam curtas de forma que todos que quiserem se expressar possam fazê-lo. Para tanto, procuramos fazer intervenções para garantir o respeito na hora da fala, o que nem sempre acontece: no debate as situações de discriminação aparecem ou reaparecem. Nestes momentos, aproveitamos para, com sutileza, mostrar o que se repete e o que estamos denunciando e, ao mesmo tempo, fazendo. Em alguns debates tivemos situações de um jovem pedir desculpas para outro publicamente por algum tipo de discriminação realizada ou um jovem que pede a palavra para se manifestar em nome de outro que ali, do lado, está chorando com dificuldade de se expressar. Outra situação que nos impressionou foi o caso de uma jovem em cadeira de rodas com muita dificuldade de fala e de coordenação motora que pede a palavra e afirma, "mas eu sou bonita, e ninguém mais vai me destratar...", sua fala é recebida com palmas emocionadas de todos os presentes... Muitas vezes o debate funciona como expressão no "aqui e agora" diante de situações representadas teatralmente "aqui e agora". Augusto Boal defendia a importância da prática teatral de cidadania quando no palco ou na plateia o espectador podia exercer o direito a se expressar e se colocar no lugar do oprimido na experiência e no exercício de poder sair desse lugar.

\section{Parte 3: Cartas}

Em seguida distribuímos pranchetas, papel e caneta e pedimos que cada jovem escrevesse uma carta para quem quiser alguém imaginário, fictício ou não, e que nessa carta contasse que foi assistir MERGULHO e de que forma o espetáculo mexeu com ele/ ela e que caminhos poderia propor para as questões que a peça levanta.

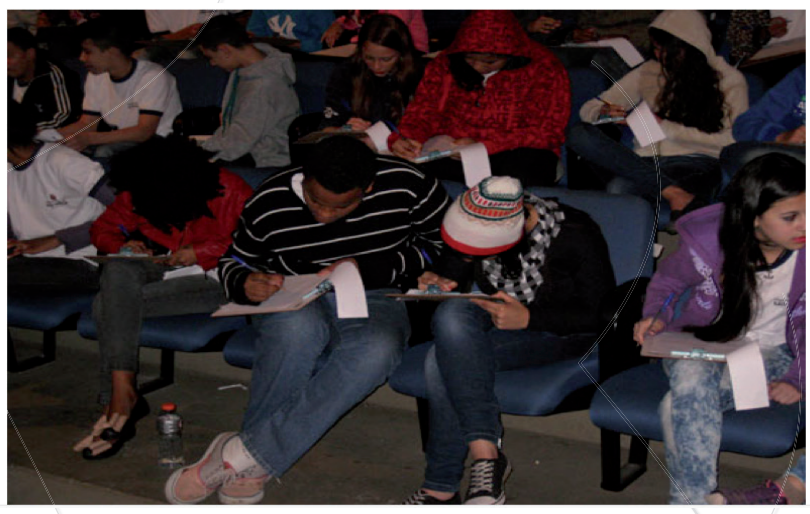

Alunos escrevendo as cartas/ redações ao final do espetáculo

Colocamos a trilha sonora da peça de fundo e nos aproximamos deles quando nos chamam para esclarecer dúvidas, para conversar sobre as cartas para ouvir e ajudar nas eventuais dificuldades. A maior parte do público escreve, vemos alguns com dificuldade de concentração ou de desenvolvimento da escrita, mas recebemos cartas de mais da metade dos espectadores. $\mathrm{Na}$ entrega das cartas há também a despedida. Formam-se rodinhas curtas de conversa, alguns gostam de tocar os acessórios ou o cenário, enquanto promotores da experiência teatral nos despedimos, guardando dentro de nós um novo vínculo recém-adquirido.

A proposta que inclui a Oficina com professores, o espetáculo, debate as cartas e posteriormente nova Oficina fazem parte de uma concepção que nomeio como Pedagogia de Encontro onde acredito ser possível que os afetos na relação pedagógica enriqueçam os processos de ensino-aprendizagem (MARKO, 2018).

Gostaria de compartilhar uma das cartas que recebemos da Amanda Yamauti Enomoto do CEU EMEF Casa Blanca ${ }^{10}$. O texto por si só é forte e claro. A peça pode ter potencializado a possibilidade da jovem se expressar e compartilhar seu anseio por uma sociedade melhor e sem preconceitos:

A todos aqueles que se sentem inferiores, Hoje assisti uma peça maravilhosa, em muitos pontos me identifiquei, ela abordava vários tipos

10 Esta, assim como as outras cartas apresentadas neste texto, foram premiadas no Concurso de Cartas da Bnai Brith. Os autores autorizaram a publicação de seus textos. 
de preconceito, em alguns pontos os colocaram de forma cômica, que deveria ser o jeito de ver as pessoas preconceituosas.

Nessa peça os atores representavam minorias que são obrigadas a lidar com pessoas de "mente pequena", pessoas que não aceitam e criticam que somos diferentes, diferentes em pontos incríveis.

Nossa sociedade tem que aprender o que é o respeito, tem que entender que os inferiores são os preconceituosos, que ainda não aprenderam que os padrões são os que quisermos.

O preconceito é inadmissível, não somos obrigados a conviver com ele, por isso devemos exterminá-lo, o preconceito mata! O preconceito traz uma dor emocional que deve acabar! Como acabar com o preconceito? Não há uma maneira imediata, devemos aprender a nos desconstruir, temos que entender que o preconceito é real e afeta todos nós, todos os dias! Se há um modo de para com isso, é acabando com ele! O futuro somo nós e só nós somos capazes de mudarmos nossos pontos de vista, basta abrir os olhos para enxergar o que a sociedade tenta esconder, chega de discriminação, não podemos tolerar.

Racismo mata todo os dias! Machismo mata muIheres todos os dias! Preconceito mata e abuso! Se desconstrua, respeite, só a educação, pode dar um fim nisso!

P.S.: Obrigada pela peça maravilhosa, obrigada pela oportunidade de assisti-los.

Grata, Amanda

Recolhemos nosso cenário, figurinos, equipamentos e cartas e voltamos para o centro de São Paulo. Na Van de volta dedicamos nosso tempo para fazer uma avaliação informal tanto sobre como foi a apresentação (novas percepções, alguma dificuldade, descobertas, reações novas dos espectadores, etc.) quanto do próprio debate. Essas ideias são registradas para futuras melhorias para uma próxima apresentação.

A parceria da Secretaria Municipal de Educação foi essencial para a realização do Projeto:

Esse projeto abraça a parte mais importante da rede municipal que são os alunos. Então ele chega até os alunos para refletir o que é ser um cidadão, que é que é ter direito, o que são direitos humanos dentro da escola. Os alunos se colocaram, choraram, se emocionaram. Trouxeram a família para dentro disso, se aproximaram dos professores. Fizeram redações, alguns tem dificuldades de escrita, entregaram-se na escrita da melhor forma possível porque é de o interesse dele, e se sentiu representado nesse tema Thiago Sousa da Cruz/Secretaria Municipal de Educação de São Paulo

Assim, a Secretaria Municipal de Educação demonstra como avaliou de forma positiva o projeto, evidenciando que não é só a instituição que nos apoia (Bnai Brith) ou o grupo de artistas que valorizam o projeto, mas que a legitimação do projeto Mergulho se encontra também nos discursos de pessoas de fora também, inclusive de pessoas que trabalham cotidianamente com educação.

A experiência teatral é transformadora não apenas para alunos e professores, mas também para os atores, principalmente no que concerne a troca com o público jovem, veremos alguns depoimentos:

Mergulho é transformação e descoberta. É um mar de dúvidas e incertezas que prontamente se torna calmaria no encontro com o meu e tantos outros "eus".. Uma eterna busca, linda e necessária. Que a vida seja sempre um grande e incessante MERGULHO.

(Gabriela Oliveira, personagem da Lila, descendente de negros e indígenas)

Mergulho está sendo uma oportunidade de olhar a diferença que há nos outros e em mim, com cada vez mais amor e empatia. Questionar, rever meus conceitos, preconceitos e crescer como pessoa e artista. (Guillermo Alves, personagem do Daniel, jovem judeu)

Eu sei que a arte tem o poder da transformação, mas descobri fazendo Mergulho que a arte também tem o poder de curar, de resgatar e preencher. Mergulho resgatou uma fase da minha 
vida que eu tinha pulado, a minha adolescência. Hoje sinto que essa fase habita em mim novamente. (Leonardo Trovão, personagem do Jeremias, nordestino)

Percebemos e confirmamos por meio dos debates e da redação das cartas a possibilidade das transformações identitárias a partir de uma experiência teatral e de seus benefícios para a construção de uma sociedade melhor.

\section{Parte 4: Oficina de Professores 2}

Após uma semana da apresentação, realizamos um novo encontro com os professores que haviam participado das oficinas prévias ao espetáculo. Conversamos sobre como foi a apresentação da peça, sobre a reação e envolvimento dos alunos, como foram os projetos desenvolvidos nas escolas. Os professores mostraram os projetos desenvolvidos individualmente ou coletivamente através de um suporte audiovisual produzido por eles. Comentamos e celebramos os resultados.

Em um segundo momento, propusemos a leitura das cartas dos alunos escritas após o espetáculo, dividindo os Professores em grupos por escolas. Desta forma, os pequenos grupos de professores tinham acesso aos textos de seus próprios alunos. Emocionados os participantes da Oficina transitam pelas narrativas e também mergulham em novas histórias. Cada grupo escolhe duas ou três cartas significativas para compartilhar depois com o grupo todo.

Uma das cartas que se sobressai é a de Henrique Sabina de Carvalho do CEU Pêra Marmelo:

Querido Planeta Terra,

Escrevo-Ihe esta carta para falar sobre o que eu sinto neste mundo.

Outro dia na escola teve uma peça de teatro, e acho que o tema poderia ser, "Ser diferente", e essa peça me chamou muita atenção pelo seguinte: ao mesmo tempo que somos iguais, somos diferentes. Existem pessoas que não são felizes sendo diferentes, mas a verdade é que as pessoas em volta dela é que o fazem se sentir excluído e muitas vezes discriminado.

As pessoas não vêm como elas são maravilho- sas sendo diferentes. Eu admito que devo ter um pouco de preconceito, mas no mundo onde nós vivemos quem não tem, é normal hoje em dia, e isso é lamentável. Eu faço o máximo para acabar com o meu preconceito, eu acho que é a sociedade que faz nós termos preconceito, e acho irônico isso, nós mesmo fazemos preconceito, até os que não se consideram preconceituosos.

E o preconceito será difícil de vencer, porque os próprios adultos influenciam as crianças a ter preconceito. Existe uma parte na peça onde os 3 adolescentes entram no espelho e saem em um mundo sem preconceito, sem julgamento e com felicidade, acho que com o mundo em que vivemos, só assim mesmo para se livrar de preconceito!

Abraços, Henrique

A carta de Henrique foi um dos textos (dentre uma grande parte) que surpreendeu os professores por apresentar uma narrativa diferente da forma como o aluno se expressa no espaço escolar. Desta forma, as cartas, neste contexto, revelaram aos professores um novo olhar pedagógico sobre os alunos, identificando a potencialidade produtiva dos jovens.

Algumas das cartas foram compartilhadas entre todos os professores e nos surpreendemos com os conteúdos elaborados, contundentes e singulares. Ademais, nos admiramos com os destinatários das mesmas: Deus, minha mãe, a mim mesmo, ao Presidente do Brasil, ao Planeta Terra. Em torno de duas mil cartas foram reunidas, as quais serão, eventualmente, publicadas no próximo módulo de apresentações.

Outra carta revelou o impacto da peça em uma jovem. Camila Lima Silva da EMEF Victor Civita se sentiu bastante representada na personagem da Lila, sobretudo pela sua origem africana:

Olá sociedade do presente, do passado e do futuro gostaria de dizer a vocês que hoje eu assisti à peça Mergulho, uma peça emocionante, engraçada e que retrata a vida de muita gente na questão do preconceito racial, social, de origem, entre outros tipos de preconceito.

Eu me identifiquei muito com a personagem Lila 
de origens africanas, não, eu não tenho origem africana, mas sofria e sofro a respeito da minha cor, do meu cabelo, da minha altura, e, como ela, às vezes também penso que sou um erro, que o fato de eu existir foi um engano.

Essa peça abriu meus olhos, meu coração, minha alma de um jeito tão lindo, me fez pensar que a única coisa feia que existe em mim não é o fato de eu ser negra, de eu ter cabelo crespo, mas sim, o fato de eu não aceitar as minhas raízes.

A solução que eu proponho, além de assistir à peça, é conhecer um pouco mais da sua origem, da sua história, pesquisar o que as pessoas boas iguais a você fizeram, para ter orgulho de quem você é e contar para os outros o que os seus antepassados fizeram.

Para a sociedade presente, deixo e proponho a vontade de mudar o futuro, de fazer acontecer aquilo que você acredita.

Para a sociedade passada, deixo o conforto que serão honrados pela sociedade presente.

Para a sociedade futura, peço a vocês que sejam compreensíveis com aqueles que sofrem e que já sofreram.

As narrativas dos professores sobre as reações dos alunos após a apresentação sobre como a peça impactou na questão dos preconceitos no cotidiano reforçam nossa convicção sobre a importância do que estamos desenvolvendo com todas as suas etapas. Por isso, a cada professor foi solicitado que também escrevesse a sua carta de como este processo de um mês, com todas as etapas, o mobilizou. Em seguida, o grupo compartilhou lendo em voz alta, todos as cartas e um novo momento de emoção instalou-se na dinâmica. Textos fortes manifestaram a intensidade da experiência: "debaixo da pele de cada um de nós existe carne, sangue correndo pelas nossas veias e um coração batendo dentro de nós, cada um perfeito do jeito que é..." (Nátila Morais, CEU Cidade Dutra)

No momento em que a gente leu as cartas, percebemos que pelo menos a solidariedade é uma coisa que já se expandiu de uma forma mais ampla de que o normal. Um professor Leo- nardo, comentou comigo que achou fantástico o momento em que os atores trazem os espelhos para o público se olhar neles nunca tinha assistido um espetáculo em que tivesse esse nível de interação...ele sofreu bulling durante a infância, ele falou puxa vida, isso é tão interessante, eu não sei, talvez se eu tivesse tido isso quando era menor, talvez as coisas fossem diferentes, talvez eu pudesse pensar de outra forma, meus colegas também. (Professor Marcos Vinicius Salinas, CEU Cidade Dutra)

A forma como me identifiquei com a peça foi uma forma rara para mim e imensurável. Essa apresentação de teatro me trouxe uma coisa que nenhum jornal, documentário e pessoa nenhuma conseguiria me fazer entender: é o que o simples fato inexplicável de nos sentirmos às vezes não quer dizer que estamos sozinhos no mundo (Professor Sergio Lobo Cerqueira Professor EMEF Anália Franco Bastos)

Vô, não conheço o senhor e nem da tua história, mas eu queria que o senhor soubesse da segunda guerra mundial, quem foi Hitler e o que ele foi capaz de fazer. (Professora Nátila Morais, CEU Cidade Dutra)

Numa rodada final cada professor pensou e propôs alguma forma de continuidade pessoal ou em grupo interdisciplinar, ao projeto desenvolvido. Conversamos e refletimos de que maneira as novas ideias poderiam ser inseridas no planejamento escolar e junto à direção institucional.

Um depoimento que encerra nosso vídeo institucional ${ }^{11}$ do projeto expressa tanto o valor do projeto como o potencial de sua continuidade:

A grata surpresa foi de que mais sementes foram plantadas do que a gente tinha imaginado Como professora sinto a necessidade de ampliar meu próprio no olhar dos meus aluno na esperança talvez utópica que possa existir uma

11 O projeto MERGULHO contou com a elaboração de um vídeo para melhor divulgação. Nele, constam imagens de cada uma das etapas, assim como depoimentos dos diferentes segmentos que dele participaram. Disponível em: https://vimeo. com/142823326 


\section{revista educação}

transformação social para assegurar que a vida de outro ser humano tenha o mesmo valor que a nossa e para isso o projeto não se esgota nem agora nem nunca porque para mim se tornou um projeto de vida (Regiane Andrade, Profa. EMEF Plácido de Castro)

Constatamos com esta experiência ampla a importância e o significado de interagir teatralmente com jovens e adultos, sobretudo no universo da educação pública. Verificamos que a participação ativa de alunos e professores, por meio da livre expressão (Oficinas, debates, cartas e como espectadores em geral) proposta de maneiras diferentes da forma escolar, constitui-se como uma maneira de acesso à cultura a setores pouco favorecidos, como criadores e como receptores. Desta forma, todos temos papel ativo na construção de uma reflexão permanente sobre as problemáticas sociais que invadem nosso cotidiano.

A nossa peça finaliza com o texto a seguir e uma frase de Guimarães Rosa e composta com um pensamento nosso:

Mergulho. Ir bem fundo. Conhecer os cardumes mais lindos, mais estranhos. Sem distinção, restrição, racismo ou qualquer coisa do tipo. Se do jovem de hoje depende o futuro, quero se jovem hoje, não o futuro amanhã.

Um dia, acreditamos que o preconceito irá acabar e até lá, existirão pessoas que irão exigir respeito. Prazer, somos algumas delas! "]

QUEM PROCURA A BUSCA NÃO RECUSA A TRAVESSIA

E FAZER MERGULHO É UMA SUPER TRAVESSIA!!!!!!

(Os atores, dirigem-se à plateia e com espelhos de acrílico grandes convidando-os a se olharem no espelho, inclusive junto com eles, os personagens. MÚSICA.)

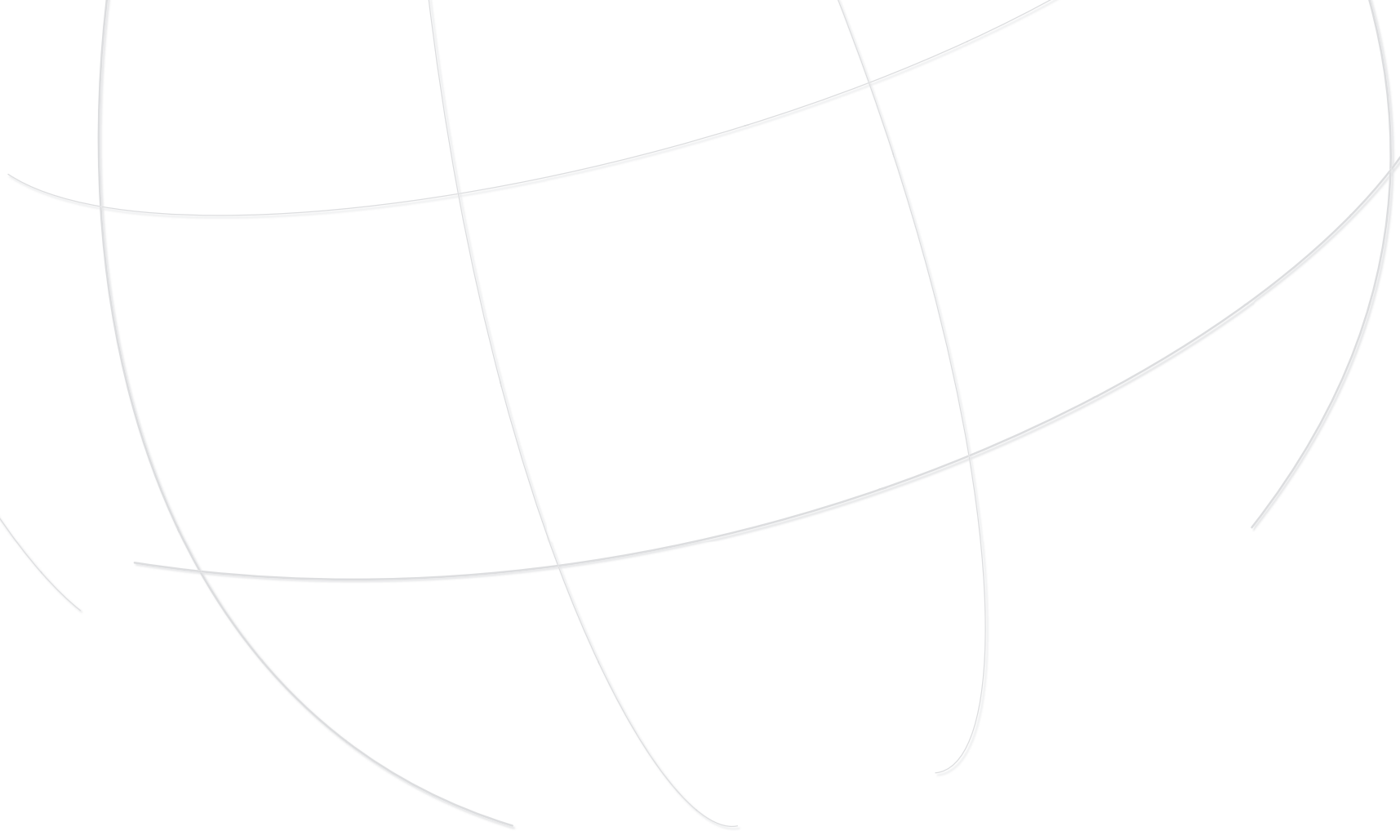




\section{revisista educação}

\section{REFERÊNCIAS}

BAUMAN, Zygmunt. Modernidade e Holocausto. Tradução de Marcus Penchel. Rio de Janeiro: Jorge Zahar, 1998.

LARROSA-BONDIA, Jorge. Notas sobre a experiência e o saber de experiência. Rev. Bras. Educ. [online]. 2002, n.19, p .20-28. Disponível em: http://dx.doi.org/10.1590/S1413-24782002000100003. Acesso em: 19 mai. 2019.

BOAL, Augusto. Estética do oprimido. Rio de Janeiro: Gamond, 2009.
JARES, X. R. Pedagogia da convivência. São Paulo: Palas Athenas, 2008.

MARKO, Leslie. Docência: em busca de uma pedagogia de encontro. In: RAHMEIER, Clarissa Sanfelice; SANTI, Pedro Di (Orgs). Existir na Cidade Os Contornos de si no (des) encontro com o outro. São Paulo: Zagodoni, 2018.

$\mathrm{READ}, \mathrm{H}$. A redenção do robô: meu encontro com a educação através da arte. São Paulo: Summus, 1986. 